\title{
Parametric Amplification of a 640 Gbit/s RZ-DPSK Signal
}

Lali-Dastjerdi, Zohreh; Galili, Michael; Mulvad, Hans Christian Hansen; Hu, Hao; Oxenløwe, Leif Katsuo; Rottwitt, Karsten; Peucheret, Christophe

Published in:

2013 Optical Fiber Communication Conference and Exposition and the National Fiber Optic Engineers

Conference (OFC/NFOEC)

Publication date:

2013

Document Version

Publisher's PDF, also known as Version of record

Link back to DTU Orbit

Citation (APA):

Lali-Dastjerdi, Z., Galili, M., Mulvad, H. C. H., Hu, H., Oxenløwe, L. K., Rottwitt, K., \& Peucheret, C. (2013).

Parametric Amplification of a 640 Gbit/s RZ-DPSK Signal. In 2013 Optical Fiber Communication Conference and Exposition and the National Fiber Optic Engineers Conference (OFC/NFOEC) (pp. JW2A.21). IEEE.

\section{General rights}

Copyright and moral rights for the publications made accessible in the public portal are retained by the authors and/or other copyright owners and it is a condition of accessing publications that users recognise and abide by the legal requirements associated with these rights.

- Users may download and print one copy of any publication from the public portal for the purpose of private study or research.

- You may not further distribute the material or use it for any profit-making activity or commercial gain

- You may freely distribute the URL identifying the publication in the public portal 


\title{
Parametric Amplification of a 640 Gbit/s RZ-DPSK Signal
}

\author{
Zohreh Lali-Dastjerdi, Michael Galili, Hans Christian Hansen Mulvad, Hao Hu, Leif Katsuo Oxenløwe, \\ Karsten Rottwitt, Christophe Peucheret, \\ DTU Fotonik, Department of Photonics Engineering, Technical University of Denmark, DK-2800 Kgs. Lyngby, Denmark \\ $\underline{\text { zoda@fotonik.dtu.dk }}$
}

\begin{abstract}
We report the first demonstration and characterization of parametric amplification of a 640Gbit/s RZ-DPSK OTDM signal. With proper design of the fiber parametric amplifier, errorfree amplification with less than $1 \mathrm{~dB}$ penalty has been achieved.

OCIS codes: (060.2330) Fiber optics communications; (190.4970) Parametric oscillators and amplifiers; (190.4410) Nonlinear optics, parametric processes.
\end{abstract}

\section{Introduction}

Fiber optical parametric amplifiers (FOPAs) have proved themselves as practical devices not only for amplification of optical signals with high gain, wide bandwidth and low noise, but also for different signal processing applications such as frequency conversion, demultiplexing and all optical regeneration [1-2]. In addition, the quasi-instantaneous gain response of FOPAs makes them attractive for high speed signal processing purposes. So far, the highest capacity amplified in a single-pump FOPA has consisted of 26 wavelength-division-multiplexed (WDM) return-tozero differential-phase-shift-keying (RZ-DPSK) modulated signals at $43.7 \mathrm{Gbit} / \mathrm{s}$ [3]. Crosstalk mainly limits the amplification performance of WDM signals in parametric amplifiers due to four-wave mixing between the channels. In contrast, optical time-division-multiplexed (OTDM) signals can be more secured against crosstalk as all the channels are time interleaved. In this paper we demonstrate for the first time amplification of a single wavelength channel $640 \mathrm{Gbit} / \mathrm{s}$ RZ-DPSK OTDM signal using a FOPA. A gain-flattened single-pump FOPA has been designed for amplification of a $640 \mathrm{Gbit} / \mathrm{s}$ signal consisting of pulses as short as $620 \mathrm{fs}$. The amplification performance has been investigated at different gain levels. Error-free performance with less than $1 \mathrm{~dB}$ power penalty has been successfully achieved.

\section{Experimental setup}

The experimental setup for amplification of a $640 \mathrm{Gbit} / \mathrm{s}$ RZ-DPSK signal is illustrated in Fig. 1. It consists of a $640 \mathrm{Gbit} / \mathrm{s}$ transmitter, a FOPA, a nonlinear optical loop mirror (NOLM) demultiplexer and a $10 \mathrm{Gbit} / \mathrm{s}$ receiver. At the transmitter, $10 \mathrm{GHz}$ short pulses are generated from an erbium glass oscillating pulse-generating laser (ERGO-PGL) at $1542 \mathrm{~nm}$ with $~ 1.5 \mathrm{ps}$ full-width at half-maximum (FWHM) pulse width. The short pulses are amplified and launched into a $400 \mathrm{~m}$ dispersion-flattened highly nonlinear fiber (DF-HNLF) to broaden their spectrum through self-phase modulation and supercontinuum (SC) generation. The broadened signal is filtered at $1553 \mathrm{~nm}$ and $1542 \mathrm{~nm}$ with $14 \mathrm{~nm}$ and $5 \mathrm{~nm}$ optical bandpass filters (OBPFs) to generate two $10 \mathrm{GHz}$ pulse trains to be used as the data signal and the NOLM demultiplexer control pulses, respectively. The data signal is encoded at $10 \mathrm{Gbit} / \mathrm{s}$ in the RZ-DPSK modulation format and then time multiplexed up to $640 \mathrm{Gbit} / \mathrm{s}$ using a passive fiber-delay multiplexer. The dispersion accumulated in the transmitter is compensated and the signal is spectrally shaped using an optical signal processor (SP), amplified and finally input to the FOPA.

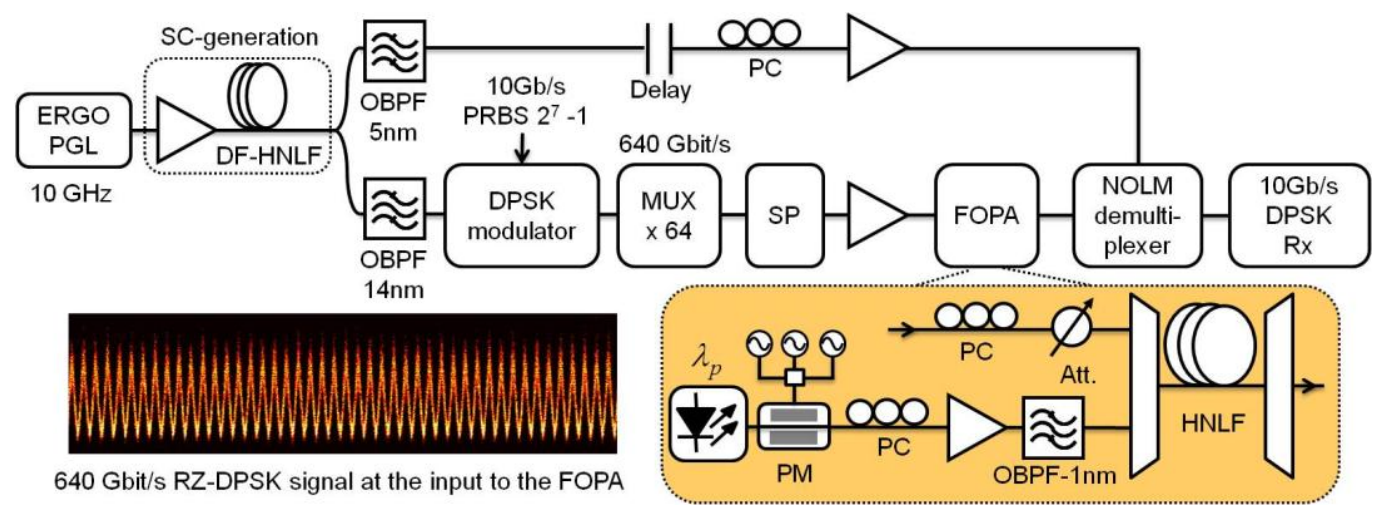

Fig. 1 Experimental setup for amplification of a $640 \mathrm{Gbit} / \mathrm{s}$ RZ-DPSK signal using a FOPA. 
At the FOPA, the pump is a continuous wave $(\mathrm{CW})$, which is phase modulated by three frequency tones (106 MHz, $288 \mathrm{MHz}$ and $1 \mathrm{GHz}$ ) in order to suppress stimulated Brillouin scattering. The pump is then amplified and filtered with a $1 \mathrm{~nm}$ OBPF, to remove out-of-band amplified spontaneous noise, and coupled with the signal into the HNLF used as gain medium by a WDM coupler. The optical signal-to-noise ratio of the pump is $54 \mathrm{~dB}$ and its input power to the HNLF is $27 \mathrm{dBm}$. The HNLF (kindly provided by OFS Denmark) is $500 \mathrm{~m}$ long, with zerodispersion wavelength (ZDW) at $1569 \mathrm{~nm}$, dispersion slope of $0.016 \mathrm{ps} /\left(\mathrm{nm}^{2} \cdot \mathrm{km}\right)$, nonlinear coefficient of $11.4 \mathrm{~W}^{-}$ ${ }^{1} \mathrm{~km}^{-1}$ and loss of $0.7 \mathrm{~dB} / \mathrm{km}$. At the output of the FOPA, the amplified signal is filtered by cascading two WDM couplers to suppress the pump wave without affecting the signal spectrum.

The amplified $640 \mathrm{Gbit} / \mathrm{s}$ OTDM signal is demultiplexed in the NOLM, operating based on cross-phase modulation induced by the $10 \mathrm{GHz}$ control pulses in a $50 \mathrm{~m}$ HNLF, resulting in $10 \mathrm{Gbit} / \mathrm{s}$ RZ-DPSK signals. Finally, the demultiplexed signals are demodulated and detected using a delay interferometer and a balanced photodetector.

\section{Results and discussion}

In order to amplify high-speed OTDM signals consisting of very short pulses, a flat gain amplifier is desirable. In FOPAs, for a given HNLF, the gain bandwidth can be tuned by tuning the wavelength and power of the pump, which determine the balance between the linear $(\Delta \beta)$ and nonlinear $\left(2 \gamma \mathrm{P}_{\mathrm{P}}\right)$ phase-mismatch terms $\Delta \beta+2 \gamma \mathrm{P}_{\mathrm{P}}=0$. First, the static gain spectra were measured using a swept $\mathrm{CW}$ probe signal for different signal input powers to the HNLF $\left(\mathrm{P}_{\mathrm{S}}\right)$, as shown in Fig. 2(a). The pump wavelength was set $2.5 \mathrm{~nm}$ above the $\mathrm{ZDW}$ at $1571.5 \mathrm{~nm}$ in order to provide a fairly flat gain spectrum around the signal wavelength centered at $1553 \mathrm{~nm}$. The $1 \mathrm{~dB}$ gain bandwidths for $P_{S}=-15 \mathrm{dBm},+7 \mathrm{dBm}$ and $+9 \mathrm{dBm}$ are $8 \mathrm{~nm}, 10 \mathrm{~nm}$ and $15 \mathrm{~nm}$, respectively. The flatter gain spectrum for higher input signal powers is due to the fact that saturation occurs faster for the parts of the signal spectrum with the highest gain. This in turn reduces the gain for this part of the spectrum, causing the gain spectrum to become flatter.
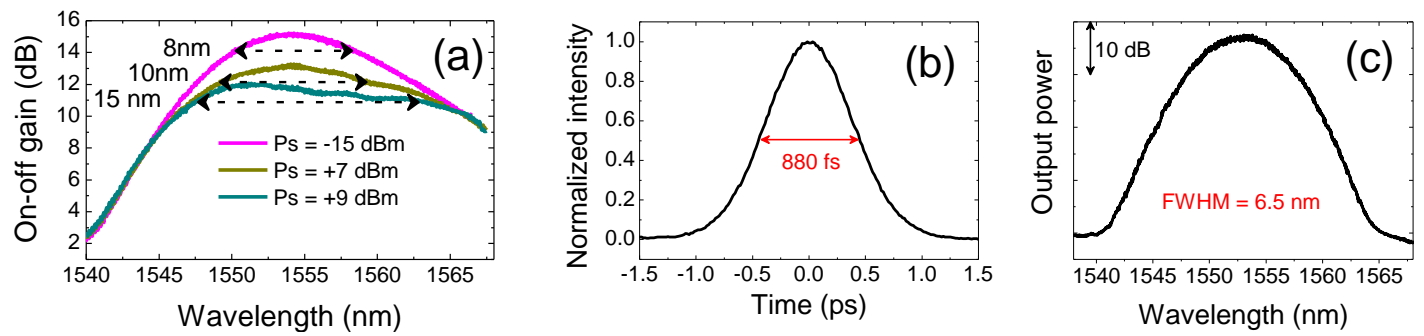

Fig. 2 (a) Static gain spectra for different signal input powers; (b) Autocorrelation trace and (c) spectrum of the 640 Gbit/s OTDM signal at the input of the FOPA.

The autocorrelation trace and spectrum of the $640 \mathrm{Gbit} / \mathrm{s}$ signal input to the FOPA are shown in Fig. 2(b,c). The input signal has a Gaussian pulse shape with $620 \mathrm{fs}$ temporal (880 fs autocorrelation) and $6.5 \mathrm{~nm}$ spectral FWHM. The output spectra of the FOPA for different signal input power levels are shown in Fig. 3. The maximum gain is achieved for the signal with $-10 \mathrm{dBm}$ average input power and is about $15 \mathrm{~dB}$ (net gain measured between the FOPA input and output, as defined in Fig. 1). The average output power and signal gain, measured in a $14 \mathrm{~nm}$ spectral window, are shown as a function of the average signal input power in the inset of Fig. 3. The signal gain is decreased by $1.7 \mathrm{~dB}$ by increasing the signal input power up to $+6 \mathrm{dBm}$.

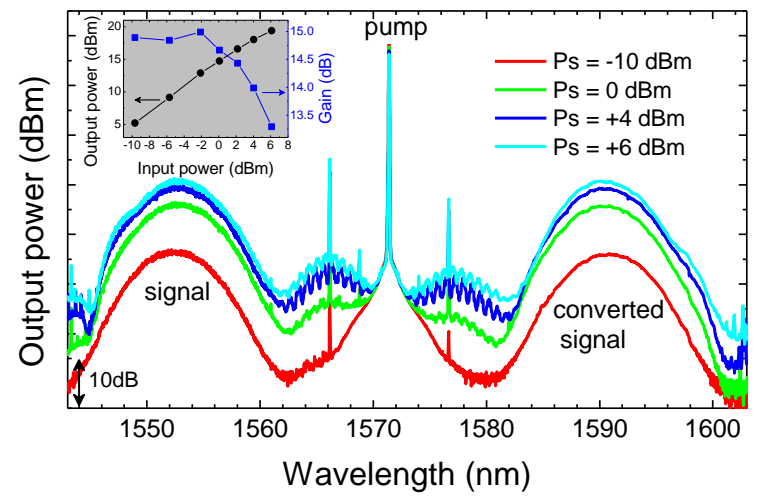

Fig. 3 Output spectra of the FOPA for different signal input powers; Inset: signal output power and signal gain as a function of signal input power to the FOPA.

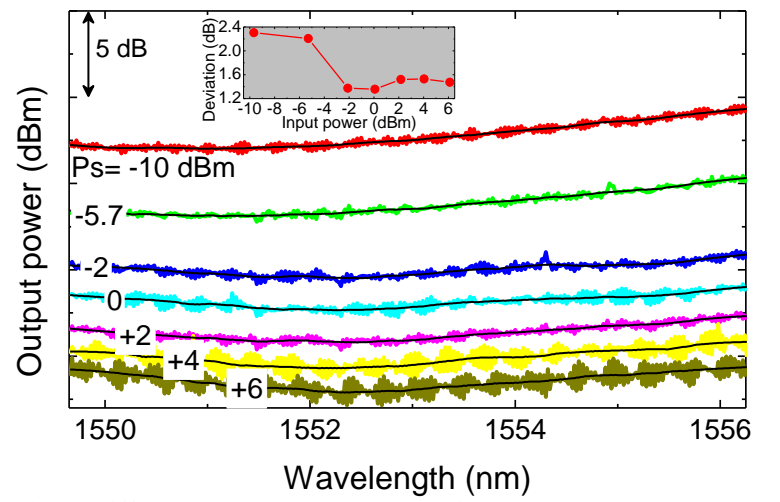

Fig. 4 Differences between the FOPA input and output signal power spectra within the FWHM range of the input signal spectrum; Inset: peak-to-peak values of the power spectrum differences. 
To investigate the effect of the gain shaping on the amplified signal, the difference between the input spectrum to the FOPA and the amplified spectrum was examined within the FWHM range of the input signal spectrum (i.e. $6.5 \mathrm{~nm}$ ) for different signal input powers, as shown in Fig. 4. The extracted peak-to-peak deviation of this power difference is represented in the inset of Fig. 4. As the signal input power increases and the gain spectrum becomes flatter, the peak-to-peak deviation consequently decreases, resulting in reduced spectral shaping. The notable point here is the clear spectral shaping of the amplified signal for input signal powers above $-2 \mathrm{dBm}$, while the signal gain (calculated based on the average input and output powers) does not show significant saturation at this power. At this power, the effect of the localized saturation of the FOPA gain does not result in a gain drop for the signal average power but does significantly alter the shape of the gain spectrum. It appears that, at a signal power of about $-2 \mathrm{dBm}$, it is possible to achieve both high average gain and a flat gain spectrum for this FOPA configuration.

Fig. 5(a) shows the results of bit error ratio (BER) measurements for the $10 \mathrm{Gbits} / \mathrm{s}$ demultiplexed signal as a function of the average received power at the input of the demultiplexer. The back-to-back curve was measured when the pump was off and the input signal power to the HNLF was set to $+5 \mathrm{dBm}$. The receiver sensitivity at a BER of $10^{-9}$ of all the 64 demultiplexed channels is shown in Fig. 5(b). Sensitivities for all the channels are spread within $\sim 2 \mathrm{~dB}$. The rest of the measurements are performed for channel number 2 with $-17.1 \mathrm{dBm}$ back-to-back sensitivity. Amplification with $15 \mathrm{~dB}$ net gain and less than $1 \mathrm{~dB}$ power penalty compared to back-to-back is successfully achieved for $\mathrm{P}_{\mathrm{S}}=-10 \mathrm{dBm}$. The performance of the system is even closer to the back-to-back case when the signal input power is increased, reaching about $0.1 \mathrm{~dB}$ penalty for $\mathrm{P}_{\mathrm{s}}=+6 \mathrm{dBm}$. In fact, the signal is more affected by the intensity noise transfer from the pump in the unsaturated gain regime. Increase of the signal input power to the FOPA reduces the pump-to-signal noise transfer [4] and flattens the gain spectrum, as shown above, resulting in better signal performance at the expense of $1.7 \mathrm{~dB}$ of signal gain.

The eye-diagrams of the $10 \mathrm{Gbit} / \mathrm{s}$ demultiplexed and demodulated signal at a BER of $10^{-9}$ are also shown in Fig. 5(c) for back-to-back and amplified signals with $15 \mathrm{~dB}$ and $13.3 \mathrm{~dB}$ gain, corresponding to $\mathrm{P}_{\mathrm{s}}=-10 \mathrm{dBm}$ and $+6 \mathrm{dBm}$, respectively.
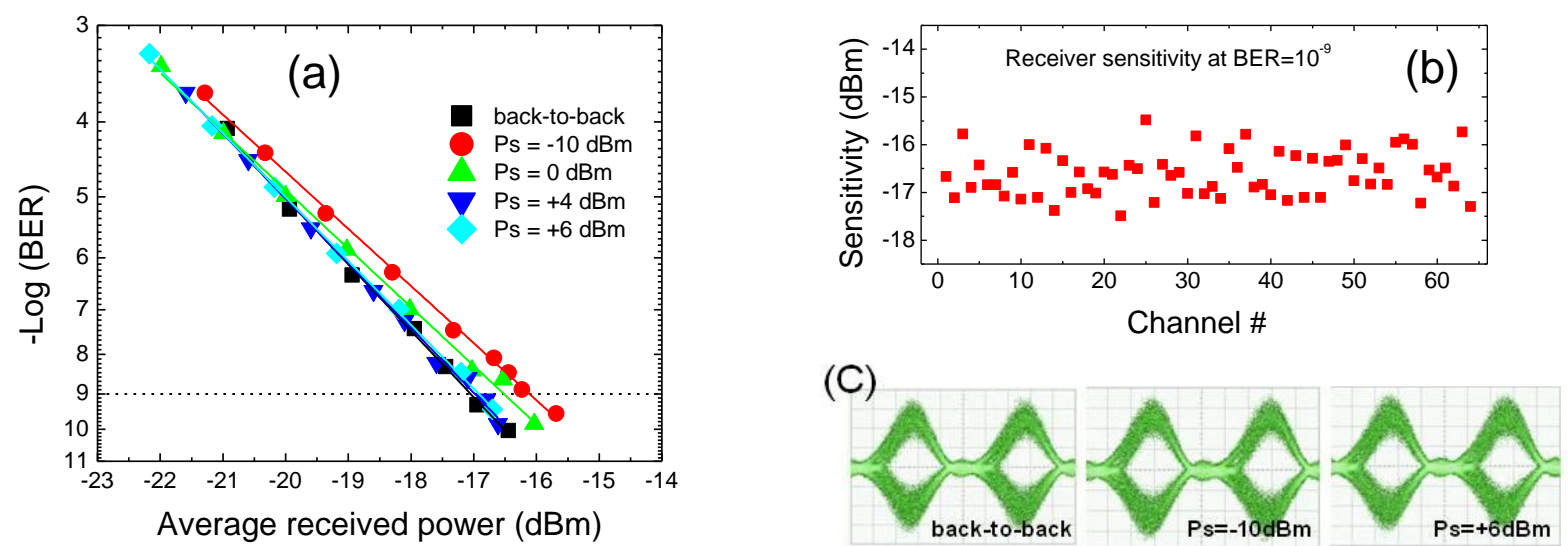

Fig. 5 (a) BER measurements for a $10 \mathrm{Gbit} / \mathrm{s}$ DPSK channel demultiplexed from the $640 \mathrm{Gbit} / \mathrm{s}$ signal; (b) Receiver sensitivity at a BER of $10^{-9}$ in back-to-back configuration; (c) Eye-diagrams of demultiplexed and demodulated signals for back-to-back and after amplification with $-10 \mathrm{dBm}$ and $+6 \mathrm{dBm}$ input power.

\section{Conclusion}

We have demonstrated amplification of a $640 \mathrm{Gbit} / \mathrm{s}$ OTDM signal in a single-pump FOPA for the first time. The performance of the amplifier for different gain levels and gain shaping has been investigated. Error-free performance with $15 \mathrm{~dB}$ net gain has been achieved with less than $1 \mathrm{~dB}$ power penalty, which was further reduced to almost no penalty when the gain was saturated by $1.7 \mathrm{~dB}$.

\section{References}

[1] J. Hansryd et al., "Fibre-based optical parametric amplifiers and their applications," IEEE. J. Select. Topics Quantum Electron. 8, 506-520 (2002).

[2] R. Slavík et al., "All-optical phase and amplitude regenerator for next-generation telecommunications systems," Nature Photon. 4, 690-695 (2010).

[3] N. E. Dahdah et al., "Fiber optical parametric amplifier performance in a 1-Tb/s DWDM communication system," IEEE. J. Select. Topics Quantum Electron. 18, 950-957 (2012).

[4] Z. Lali-Dastjerdi et al., "Pump-to-signal intensity modulation transfer characteristics in FOPAs: modulation frequency and saturation effect," J. Lightwave Technol. 30, 3061-3067 (2012). 